\title{
A DESIGN METHOD OF THE SEA WALL AND WATER APRON BY THE TSUNAMI
}

\author{
Hiroyuki Katou, The Japanese Institute of Fisheries Infrastructure and Communities, katou@jific.or.jp \\ Hiroyuki Iwase, ECOH Corporation, iwase@ecoh.co.jp \\ Hideo Matsutomi, Akita University, matsu@gipc.akita-u.ac.jp
}

\section{INTRODUCTION}

Many of the coastal conservation facilities of the fishing port were severely damaged by the wave force of the 2011 Tohoku earthquake tsunami. We evaluated the tsunami wave force by conventional hydrostatic pressure for the sea wall of the fishing port. In addition, we considered the acting force and the acting range for the water apron of the sea wall during tsunami over flow, and presented a reasonable design of the sea wall.

The tsunami wave force for the sea wall is not sufficiently examine by the seabed gradient, the position of structure and the back slope of the sea wall. Facility name of the fishing port is shown in figure 1.

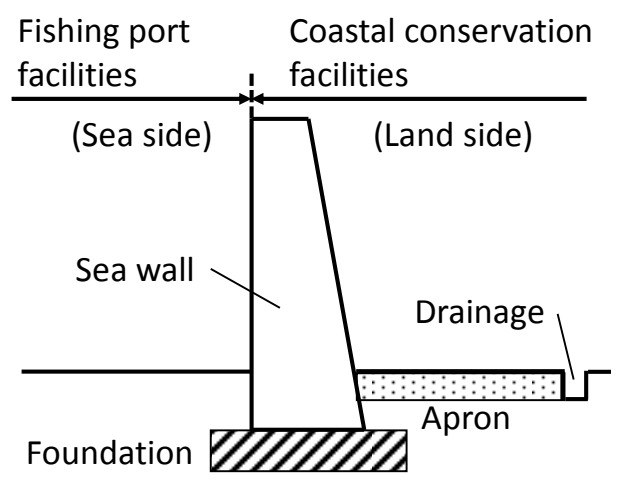

Figure 1 Facility name of the fishing port

\section{EXPERIMET AND SIMULATION}

In this study, we evaluated the acting force and the acting range of tsunami using by the hydraulic experiment and the numerical simulation model (CADMAS-SURF/2D), and presented the estimation formulas of their.

\section{WAVE PRESSURE FOR THE SEA WALL}

For the wave force by the non-overflow of tsunami (see figure 2), figure 3 is shown the relationship between Froude number $F_{r}$ and the dimensionless wave pressure coefficient $\alpha$ and $\alpha$ '. Equations 1 is the calculation formulas for the wave pressure $P_{\max }$.

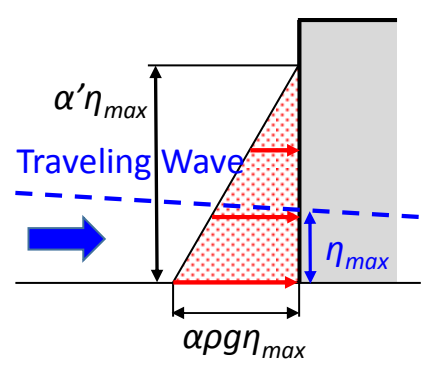

Figure 2 wave force of tsunami for structure

$$
\begin{aligned}
& \frac{P_{\max }}{\rho g \eta_{\max }}=\alpha\left(1-\frac{Z}{\alpha^{\prime} \eta_{\max }}\right), \quad 0 \leq \frac{Z}{\eta_{\max }} \leq \alpha^{\prime} \\
& \alpha=1.0+1.35 F_{r}^{2}, \quad \alpha^{\prime}=\max \{3, \alpha\}
\end{aligned}
$$

Where $Z$ is the wave acting height form ground, $\eta_{\max }$ is the traveling wave of tsunami, $g$ is the acceleration due to gravity, $\rho$ is the density of sea water.

If $F_{r}$ is unknown, use to the flow depth at shore line as $\eta_{\max }, \alpha=2.2$ and $\alpha^{\prime}=3.0$.

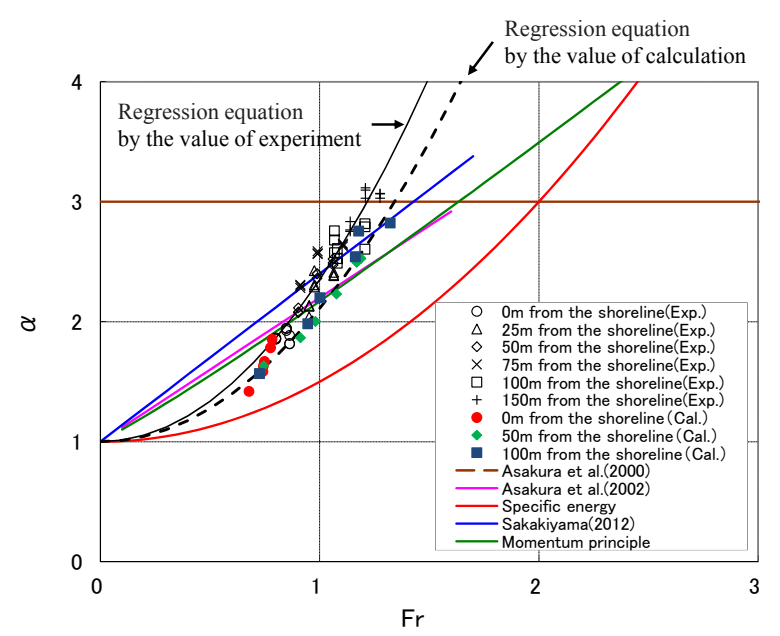

Figure 3 Relation $F_{r}$ and $\alpha$

\section{TSUNAMI ACTING TO WATER APLON}

For the wave force by the overflow of tsunami (see figure 4 ), figure 5 is shown the relationship between the overflow water depth of upstream $h_{u p}$ and the maximum pressure for wave apron $P V_{\max }$, figure 6 is shown the relationship between $h_{u p}$ and the acting range $L$.

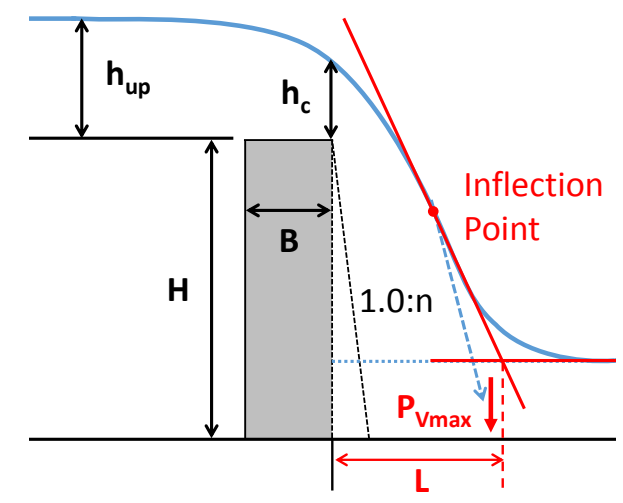

Figure 4 wave force of tsunami for apron 


$$
\begin{aligned}
& P_{V \max }=1.41 \rho g H\left(\frac{h_{u p}}{H}\right)^{0.72} \\
& L=1.85 H\left(\frac{h_{u p}}{H}\right)^{0.69} \\
& L=1.85 h_{u p}
\end{aligned}
$$$$
\text { for } 0<h_{u p} / H<1
$$$$
\text { for } 1<h_{\text {up }} / H<2.5
$$

Where $\mathrm{H}$ is the height of sea wall. The calculation example is shown in figure 7.

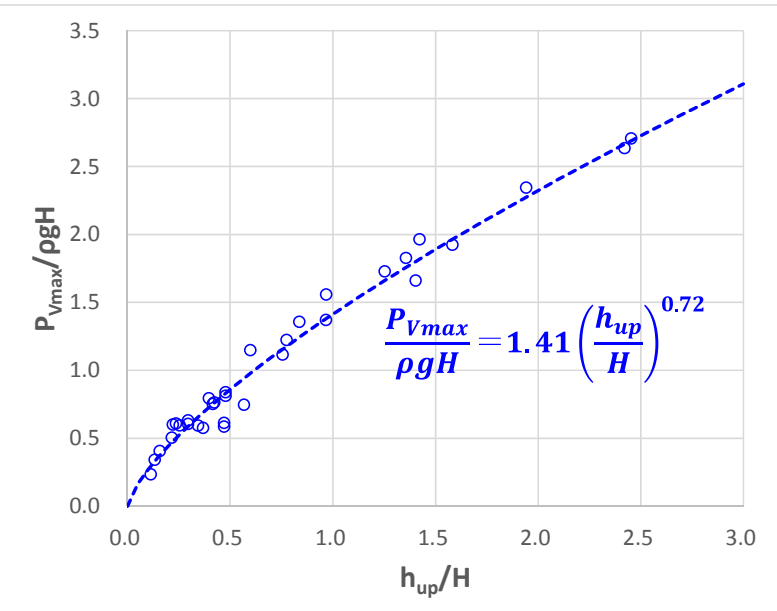

Figure 5 Relation $h_{u p} / H$ and $P_{V \max }$

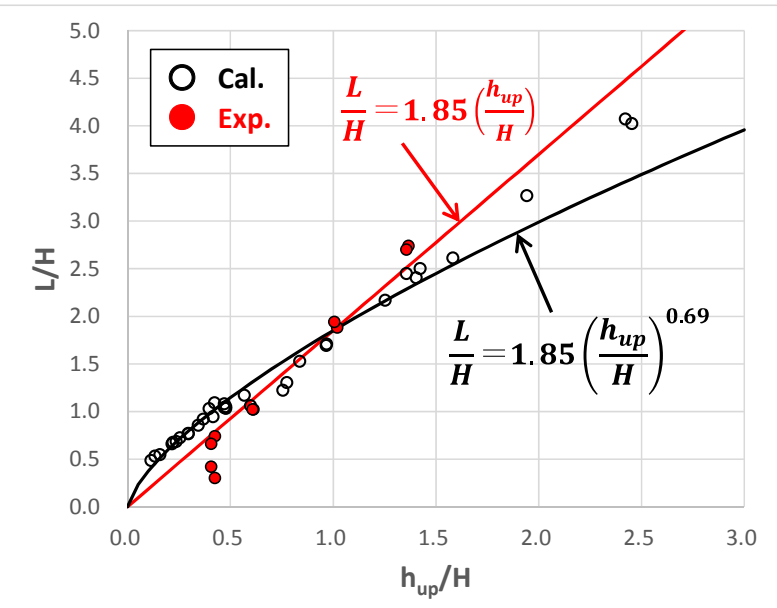

Figure 6 Relation $h_{u p} / H$ and $L$

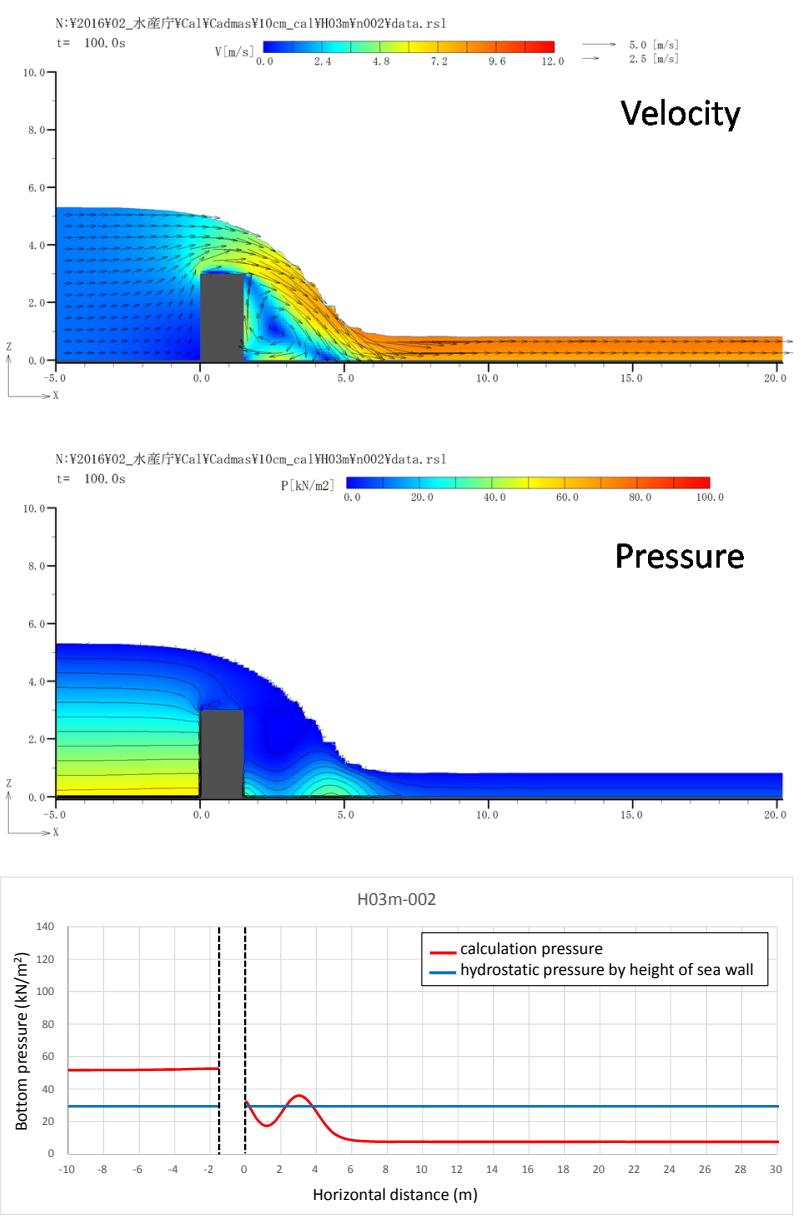

Figure 7 Calculation result example $\left(H=3.0 \mathrm{~m}, h_{c}=1.56 \mathrm{~m}, n=0\right)$

\section{CONCLUSIONS}

From these results, it is possible to calculate the acting tsunami force and the acting range for the sea wall, and the sea wall was designed efficiently by Tsunami attack.

\section{REFERENCES}

R. Asakura et al. (2000): An Experimental Study on Wave Force Acting on On-Shore Structures due to Overflowng Tsunamis, Proc. of Coastal Engineering, JSCE, Vol.47, pp.911-915.

R. Asakura et al. (2002): The tsunami wave force acting on land structure, Proc. of 28th ICCE, ASCE, pp.11911202.

T. Sakakiyama (2012): Tsunami Inundatation Flow and Tsunami Pressure on Structres, Journal of JSCE, Ser. B2 (Coastal Engineering), Vol.68, pp.771-775. 